\title{
IoT and Wireless Sensor Networking-based Effluent Treatment Plant Monitoring System
}

\author{
Md. Saikat Islam Khan ${ }^{1,2}$, Anichur Rahman ${ }^{1,2}$, Sifatul Islam ${ }^{1,2}$, \\ Mostofa Kamal Nasir ${ }^{1}$, Shahab S. Band ${ }^{3, *}$, Amir Mosavi ${ }^{4, *}$
}

${ }^{1}$ Department of Computer Science and Engineering, Mawlana Bhashani Science and Technology University, Tangail 1902, Bangladesh, kamal@mbstu.ac.bd

${ }^{2}$ Department of Computer Science and Engineering, National Institute of Textile Engineering and Research (NITER), Constituent Institute of the University of Dhaka, Savar, Dhaka, Bangladesh, \{anis_cse, b.khan_cse, and s.islam_cse @niter.edu.bd

${ }^{3}$ Future Technology Research Center, College of Future, National Yunlin University of Science and Technology, 123 University Road, Section 3, Douliou, Yunlin 64002, Taiwan; shamshirbands@yuntech.edu.tw

${ }^{4}$ John von Neumann Faculty of Informatics, Óbuda University, Bécsi út 96/b, 1034 Budapest, Hungary, amir.mosavi@nik.uni-obuda.hu

Abstract: Contaminated water became a major issue for our country over the last few decades. One of the main reasons behind this scenario is urbanization and industrialization. Every industry should have an Effluent Treatment Plant (ETP) for treating industrial wastewater and safe disposal to the environment. We implement a system that monitors whether an industry uses ETP or not. To monitor ETP, we need to monitor the untreated wastewater quality. The traditional way offers us a method that is time-consuming and inefficient. To solve this problem, we adopt a model based on Wireless Sensor Networking (WSN), which allows us to keep track of the water quality parameters in real-time. This paper proposes a water quality monitoring system that uses WSN and Internet of Things (IoT) based devices to monitor different parameters of water: temperature by a temperature sensor, turbidity by a turbidity sensor, and $\mathrm{pH}$ by a $\mathrm{pH}$ sensor. Moreover, the microcontroller of Arduino Uno R3 collects the parameter values from these sensors and transmits the values to the IoT based cloud server using the GSM module. The GSM module is also used to alert the supervisors by sending SMS in case of an emergency. Integrating modules such as sensors, Arduino Uno R3, GSM module, enhances the purpose of the desired system. Finally, we calculate the Water Quality Index (WQI) for the $\mathrm{pH}$ and turbidity data to report the water quality status. Also, we compare the WQI status with our cloud status, and it shows excellent performance.

Keywords: water quality; wireless sensor networking; IoT; smart sensor; GSM module; Real-time; plant monitoring; artificial intelligence 


\section{Introduction}

Water is one of the most vital assets for humankind. Without water, no plants or animals on earth would survive. The industry has been growing every year on the back of spiraling demand from domestic and export markets. But because of the growing rate of industry in developing countries like Bangladesh, water is constantly being polluted. Water is mostly being polluted because of the industries discharging untreated waste and effluent into the rivers and cannels. Water related diseases cause 3.4 million deaths each year across the globe, according to WHO Water Day Report. Defiled water is also responsible for the degradation of agricultural land, soil fertility loss, and increases pressure on groundwater. About 200 rivers of Bangladesh directly or obliquely received a large amount of untreated industrial wastes. The World Bank claimed that in Bangladesh, approximately $\$ 6.5$ billion losses due to untreated water, which is $3.4 \%$ of the GDP in 2015. There are many factories and industries in our country. According to a Bangladeshi daily newspaper (The daily star), the textile industry will be discharging 203 billion liters of polluted water into the river's water every year from 2021. ETP is one of the best solutions to sanctify untreated water discharged by industries and factories. According to The Daily Star, currently, 5000 ETPs are initiated in factories and industries, which cover approximately $70 \%$ of the textile units [1]. It also said that Bangladesh has around 1,200 weaving mills, 5,000 export-oriented dyeing factories, and 450 spinning mills.

We will monitor the quality of water on the industrial water discharged site. To ensure whether the water is contaminated or not, we need real-time data analysis because the sample is continuously changing. If we want to monitor this water through the lab, then the cost will be high, and efficiency will be lower. In modern times, the wireless sensor network is used in many sectors. Wireless sensor networks have received considerable attention not only in environmental sectors but also in industrial sectors [2-6]. WSN provides a massive advantage on cost because the installation and maintenance expenses are low, and the device that we use is cheaper, which required no writing [7-11]. That's why environmental and industrial monitoring largely depends on WSN technology [12-14]. We can apply this technology in water quality monitoring, which will provide us with the best approach to real-time data acquisition, processing, and transmission. In this paper, we proposed a complete WSN water quality monitoring system that will allow us to monitor the ETP. This system consists of a set of sensors such as $\mathrm{pH}$, temperature, turbidity, an Arduino Uno R3 microcontroller, GSM module, IoT based cloud server (Thingspeak). This system measures different parameters of water, such as $\mathrm{pH}$, temperature, and turbidity. In the results and discussion section, we proved that the system has a great prospect in industrial ETP plant monitoring. In this paper, Section 2 discusses the literature survey on surveying water quality. Then, Section 3 illustrates the method we have implemented. After that, our data collection procedure is in Section 4. Section 5 discusses the results obtained through this system and finally, Section 6 brings a conclusion. 


\section{Literature Survey}

In this paper, our fundamental goal is to monitor the effluent treatment plant in realtime using a wireless sensor network. So, our primary concern is to examine water to determine the water quality parameters such as $\mathrm{pH}$, temperature, and turbidity. The following papers proposed various methods to check the quality of water. This study delineated an efficient IoT-based system for measuring water quality by determining temperature, $\mathrm{pH}$, turbidity, and water level [15]. Here, the data is transmitted to a webpage using GPS and GPRS modules. Another work proposed an intelligent sensor interface for industrial WSN in the IoT environment. They monitored water purity in the pond using a light intensity sensor, digital temperature sensor, turbidity sensor by distributing multiple nodes in different areas. They utilized ZigBee wireless communication, a short communication method, for communication purposes [16]. Further, this paper claimed a costeffective, low-power transmission system for water quality monitoring in lakes around ANNABA reagent. They considered different parameters such as $\mathrm{pH}$, conductivity, temperature, oxygen concentration, measured by other Arduino-based sensors. The authors suggested a personal computer (PC) as a base station and developed a GUI using MatLab software for visualizing data [17]. This study described an automated agricultural monitoring system (iAgriMon) that uses a hybrid IoT and WSN architecture to monitor temperature and humidity parameters in a greenhouse setting [18]. For improving agricultural ecosystems, a web portal is used to analyze the obtained data. In addition, the researchers propose an intelligent irrigation control system that uses wireless sensor networks, a customized server, and a Wemos D1 small (as the main microcontroller) [19]. They applied the T-test statistical tool to see if the results are acceptable. They also compared their method to the traditional approaches, where results suggested that the proposed method outperformed all the other methods. This research described a system that employs WSN technology in the IoT platform for water resource irrigation and proper water resource usage in Precision Agricultural Farming (PAF) [20]. According to IoTbased applications, these studies presented the novel framework based on leading technologies such as Blockchain, Software-defined networks to innovative fields through IoT platforms [21, 22]. Another research claimed that throughput maximization, latency reduction, a high signal-to-noise ratio, a low mean square error, and increased coverage area promote communication between different IoT sensors. They showed that their outcomes outperform traditional IoT-based farming methods [23]. In similar work, Temperature, dissolved oxygen, and $\mathrm{pH}$ are measured by the system, which sends the data to a cloud internet platform via a router gateway and can be tracked by smart devices in real-time. This studied offered an upgraded WSN that applies a proposed algorithm in a tomato-growing greenhouse [24]. They monitored Temperature, humidity, Carbon Monoxide, Carbon dioxide, and light intensity and let users set minimum and maximum setpoints and time and date-based irrigation management. They focused on tomato crop yield has grown by $30 \%$, while Methane Gas, water, and electricity use have 
lowered by $30 \%, 24 \%$, and $10 \%$, respectively, compared to the conventional method. This research examined an innovative agricultural system based on a WSN and IoT with numerous goals, including implementing a real-time approach to reduce data loss when transmitting and receiving signals and improving the automation system [25]. Furthermore, this research suggested a clustering methodology based on a fuzzy method used in agriculture to increase node density and coverage area and optimize data link and energy consumption. They demonstrated that the strategy is realistic through simulation because it outperforms scalable conditions in the dead final node and half of the node dead [26]. Again, this study deliberated a wireless sensor-based approach named cluster head selection process into the IoT network [27]. They applied the clustering process with low energy consumption to manage the sensor data over the desired IoT network [28]. Furthermore, this paper proposed a system to inspect the quality of water of Lake Victoria Basin (LVB) in real-time by checking water temperature, dissolved oxygen (DO), $\mathrm{pH}$, and electrical conductivity in real-time, using an $\mathrm{RF}$ transceiver and GPS receiver for transmitting data in real-time [29]. Similarly, this study proposed a real-time water quality monitoring system for the River Nile by measuring $\mathrm{pH}$, turbidity, and Temperature. They show a prototype that includes a temperature sensor, $\mathrm{pH}$ sensor, turbidity sensor, Raspberry Pi, some communication technologies, a dynamic website, and a mobile application for visualization [30]. Additionally, it provided a Water Quality Monitoring System, which uses a turbidity sensor, $\mathrm{pH}$ sensor, temperature sensor, and DO sensor integrated into an Arduino Uno board. For transmitting and receiving values, they considered the LoRa module, which uses the LoRa WAN protocol. They visualized their resulting data on the Thing Speak IoT platform [31]. Their work is based on three fundamental blocks: the water quality monitoring stations, the GPRS data transmission modem, and the monitoring station. They employed an A/D converter to convert the analog signal into a digital signal. To read digital data, they use IPC. The data is sent through the GPRS modem to the monitoring station for analysis purposes [32]. Another research [33], a WQM system in which the sensor nodes are placed within the riverbed and data is transmitted to the base station using GPRS. They allow Raspberry Pi over the SPI interface for interfacing ADC. For enhancing efficiency, they use a one-wire communication protocol in temperature sensors. Moreover, a water quality monitoring process uses an uncrewed aerial vehicle (UAV) robot, which used four propellers. This UAV robot is made of an ATMega 2560 microcontroller, a temperature sensor, a ph sensor, a water turbidity sensor, a GPS sensor, a dissolved oxygen sensor, a 3DR radio telemetry transmitter. They developed a GUI at the base station for visualizing the performance of different parameter values of water [34]. Similar work, a system that uses a $\mathrm{pH}$ sensing module, Arduino UNO Board, Temperature Sensing Module, and RF Module. They presented Arduino Ethernet Shield as IoT Module, which pushes data to cloud storage. An Android OS platform-based mobile application was developed, which shows the latest $\mathrm{Ph}$ value, temperature, and time stamp. A GUI is also extended to show the graphical interpretation of those data for visualizing. 
Finally, they compared the proposed system result with a standalone RFID system [35]. In addition, they considered a sum throughput technique to present the joint maximization of energy harvest and information transmission rate where wireless information and power transfer are used to harvest the energy from radio frequency sources [36]. Similarly, they propose an online monitoring water quality system using WSN in Indonesia [37]. They evaluated water quality using Zigbee wireless communication. The $\mathrm{pH}$ and turbidity sensors determine whether water quality is good or bad [38]. They observed flood and water quality using IoT. They combined various sensors such as weather monitoring, soil moisture monitoring, and fire alarm to implement their method [39]. They projected an intelligent water quality monitoring system to prevent the contamination of the water. They build a monitoring center where data is analyzed. For data transmission, they used the GPRS method [40]. Furthermore, they planned a low-cost and real-time water quality monitoring system used in remote lakes, rivers, and other water bodies. They proceeded with DO and $\mathrm{pH}$ sensors and developed a mobile application to check the system efficiency [41]. On the other hand, these studies focused on machine learning and deep learning methods to classify water quality conditions. They also calculated the water quality index from various sensors [42, 43, 44, 45].

\section{Materials and Methods}

Wireless sensor networking is used to collect data about various applications, for example, residential security, surveillance, and ocean monitoring. The IoT motivates the rapid advancement of modern wireless telecommunication and is expected to bring avails to a legionary number of application areas, including the industrial WSN systems. The proposed system, "IoT and WSN based Effluent Treatment Plant Monitoring System," performs real-time water quality monitoring. This section represents the structure of WSN and IoT with their corresponding equipment. This system simply includes WSN sensor nodes, Microcontroller, and IoT platforms. Figure 1 expresses the simple way to monitor the water quality, where the wireless sensors module sent the data to the microcontroller module, and the microcontroller module sent the data to the central server.

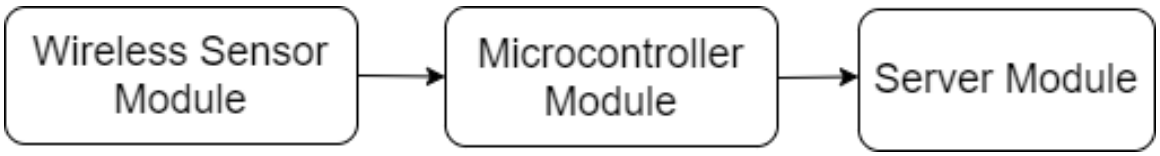

Figure 1

Basic Diagram for Water Quality Monitoring System 


\subsection{WSN Sensor Node}

The sensor node plays the main role in our proposed WSN system. It is sorted with four sensors and microcontroller units. In this system, four sensors measure $\mathrm{pH}$, temperature, turbidity, and flow, which determine the general characteristics of water. However, this method allows using more sensors depending on needs. The $\mathrm{pH}$, temperature, and turbidity sensors are interfaced with the Arduino microcontroller to measure the water quality parameter values. Figure 1 shows the basic diagram of our proposed system, where Figure 2 shows the schematic diagram of the sensor node unit of this system. The sensors are connected to the Arduino Uno board to the correct pin, which ensures correct operation and gives the result of a different parameter value of water correctly.

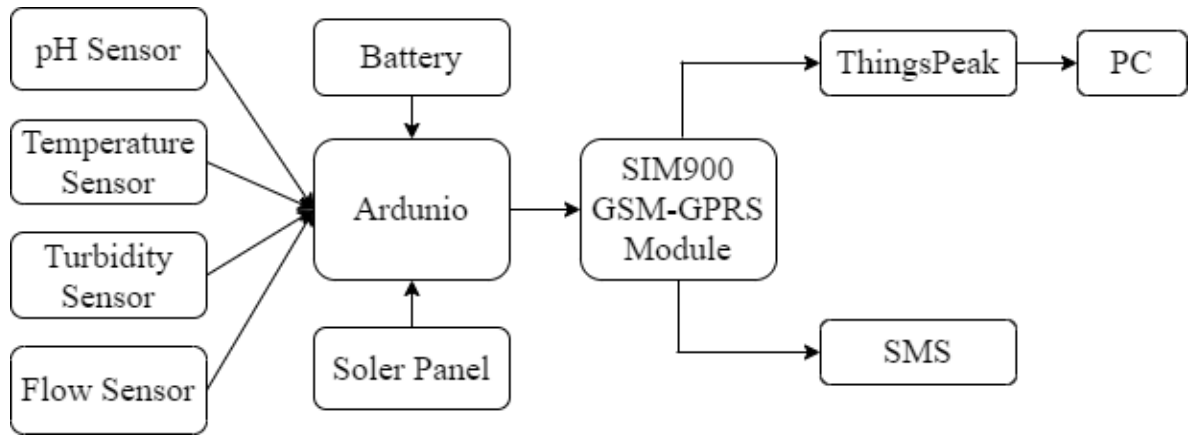

Figure 2

Real-Time Water Quality Monitoring System using WSN

\subsection{1 pH Sensor}

A pH sensor is a scientific device that is used to measure the hydrogen ion activity in water. The $\mathrm{pH}$ sensor determines $\mathrm{pH}$ by measuring the voltage level or the difference of the solution in which it is immersed. The logarithmic scale of $\mathrm{pH}$ starts from 0 to 14. At level 7, we find the water source level is natural. When the level is less than seven, then the water has acidic solutions, and if the level is greater than seven, then the water has alkaline solutions. A pH sensor got two electrodes, which are the measuring electrode and the reference electrode. The positive end of the battery is paired with a measuring electrode, and a negative end is paired with a reference electrode. The reference electrode will not be changed because it always provides a fixed voltage when the $\mathrm{pH}$ meter is dipped into the solutions. The measuring electrode provides voltage and sensitivity to the hydrogen ion. If the temperature changes, then the differential voltage of the electrode also changes.Therefore, we need a temperature sensor. 


\subsubsection{Turbidity Sensor}

The turbidity sensor is the measurement of water transparency. It is used to measure total suspend solids (TSS) in water by sending the light beam into the water body. This light will then fling by any suspended particles such as soil, silts, clay, which enter the water and affect the water body. A light detector is used to measure the amount of light that is being reflected back at it. Turbidity is measured in Nephelometric Turbidity Units, which is known as NTU. Turbidity values from the turbidity sensor can be higher or lower. Higher turbidity means there are lots of suspended solids in the water, and light cannot pass through it, which means the water is impure. Lower turbidity means the water is pure because there are fewer suspended solids in the water, and light can easily pass through it.

\subsubsection{Temperature Sensor}

Temperature is measured through an electrical signal in the temperature sensor. As the voltage differences of electrodes change with temperature, a temperature sensor is needed. The correction for changing in voltage can also be done by this sensor. It requires RTD (Resistance Temperature Detectors) and a thermocouple. The RTD is a variable resistance that will change the electrical resistance indi-rectly proportional to the change in the temperature in a linear manner where the thermocouple is made by two dissimilar metals which are used to generate the electrical voltage indirectly proportional to the change in the temperature. For pure water temperature value is 27 degrees Celsius. Table 1 represents the $\mathrm{pH}$, temperature, and turbidity value and shows in which condition water is pure or polluted. The general guideline of $\mathrm{pH}$, temperature and turbidity value in pure water is suggested by WHO [46].

Table 1

WSN PARAMETERS VALUE

\begin{tabular}{|l|l|l|}
\hline Parameter & Treated Water & Polluted Water \\
\hline $\mathrm{pH}$ & $6.5-8.5$ & $<6.5$ and $>8.5$ \\
\hline Temperature & $20-35^{\circ} \mathrm{C}$ & $<20^{\circ} \mathrm{C}$ and $>35^{\circ} \mathrm{C}$ \\
\hline Turbidity & $<10 \mathrm{NTU}$ & $>0 \mathrm{NTU}$ \\
\hline
\end{tabular}

\subsubsection{Flow Meter}

Flow meters measure how much water has gone across it. There are different types of flow meters. Among them, Krohne's electromagnetic flowmeters can be used to measure both flow volume and flow rate. This flow meter consists of the sensor and converter where the sensor consists of measuring tubes, poles, induction coils, iron core, and shell. It works on the principle of Faraday's law of electromagnetic induction. Here, digital pulses act as flow volume and can be paired with a microcontroller using a digital I/O pin. We can set 2 flow meters in our proposed system. One in the discharging point of ETP and the other in the discharging point 
of the water tank. Then, we will compare the total amount of water passed through them. If their volume is significantly different, then an emergency SMS can be sent to the base station.

\subsection{Microcontroller Module}

Arduino Uno R3 isused as a microcontroller module for this system, which includes a microcontroller and a $\mathrm{C}$ program that determines the behavior of the WSN sensor node. Arduino Uno R3 Microcontroller is a free platform that is flexible, convenient hardware, and easy operable software which is used to acquire sensor data. Arduino Uno Board will analyze and process the data and send it to the server. Whenever the $\mathrm{pH}$ value goes beyond the 6-8.5 range, Arduino will send an SMS to the authority via the GSM module. Similarly, whenever turbidity value goes beyond the range, as shown in Table 3, the GSM module will send a message about the status of the water quality to the authority.

\subsection{SIM900 GSM-GPRS Module}

A GSM or GPRS module is a circuit or chip which is used to establish communication between a mobile device or a computer with a GSM or GPRS system. To send the sensors data from the Arduino to the pc, we need a GSM module that is compatible with the Arduino. It allows sending SMS via UART using AT commands. We can create a send SMS() function in the Arduino microcontroller board by using AT commands. This function uses the AT commands such as AT $+\mathrm{CMGF}=1$ and AT $+\mathrm{CMGS}$ to send the SMS. A SIM-CARD is attached to the module and is used to send the message to the authority. This module can connect to the internet over the GPRS network. GPRS network provides moderate-speed data transfer using unused time division multiple access (TDMA). SIM900 GSM-GPRS module can transfer sensors data from the Arduino to the IoT cloud server platform using HTTP POST-GET request.

\subsection{IoT Platform}

An IoT platform is a technology which got more than one layer. It communicates data between a hardware device and cloud storage [47]. Currently, the IoT platform gives users a built-in feature, which makes it easy to create program applications for connected hardware devices, and it also takes care of cross-device compatibility, data security, and scalability. Key technologies that are related to the IoT are sensor node technologies, including wireless sensor networks, miniaturization, and nanotechnology. As IoT is related too many wireless sensor devices, it produces a large number of data, which is also processed by IoT. Basically, IoT consists of three layers 1) Application layer 2) Network layer 3) Perception layer [48]. The data acquisition interface is designed by the perception layer of IoT, which includes sensors, cameras, RFID readers, and various data collection terminals. The data 
acquisition interface plays a vital role in the collaboration and integration of environments and for collecting the sensor's data. Effluent Treatment Plant can be monitored by the water quality monitoring method. Water quality monitoring is one of the major IoT application fields because it adopts sensors to determine the water quality factor value and detect pollution. That collection of sensors data can be transmitted to the IoT cloud server using the GSM module.

\subsubsection{Thingspeak}

There are so many IoT platforms that we can use to store, process, and analyze the sensor's data. Some of the IoT platforms are Microsoft Azure IoT,Amazon Web Service or AWS, Google Cloud Platform, Thingspeak, Thingworx, Cisco to IoT CloudConnect, etc. Among them for our method, we use the Thingspeak cloud server, which is an open data platform and API for the IoT, which will help you to store, collect, process, analyze and act on data from sensors. It is also user-friendly and provides data security and free access to the cloud. The sensor node will send data to the cloud to store in the channel of Thingspeak. Thingspeak channel supports eight channels in which we use three channels, such as $\mathrm{pH}$, Temperature, and turbidity. Through this process, we can analyze, visualized, and calculate new data and also interact with social media. The data are coming from the sensors organized in the cloud in the form of plots, charts, graphs using analytical tools online. Thingspeak also provides access to MATLAB to provide sensor data. One can react both in new data and the raw data in each channel and also can help the devices to execute by using the commands. Thingspeak cloud server can send the data to the PC in an EXCEL form which is real-time. The collection of the sensor data in realtime is shown in the data collection section.

\subsection{WSN Power Supply}

In the WSN system, sensor nodes are situated at a remote distance. So the power supply becomes a major issue here. There are many methods to power the sensor node. Using a battery is one of them. But the battery energy is limited, and replacing batteries is not easy. Different energy harvesting methods like solar panels can be used to recharge the battery. This system uses a $3.7 \mathrm{~V} 6 \mathrm{AH}$ rechargeable polymerlithium-ion battery, which is used to power the sensor nodes. This battery has a longer lifespan and also has an excellent self-discharge rate. We will use a solar panel in the future to recharge the battery so that it can save battery power.

\subsection{WQI Calculation}

A detailed method of WQI calculation can be found [49], but a brief discussion of this method can be found here. To evaluate water quality, we use the scale, which is proposed by Ramakrishnaiah et al. [50] that is shown in Table 2. 
Table 2

Water quality scale based on WQI

\begin{tabular}{|l|l|}
\hline Water Quality Class & WQI value \\
\hline Excellent & $<50$ \\
\hline Good & $50-100$ \\
\hline Poor & $100-200$ \\
\hline Very poor & $200-300$ \\
\hline Unsuitable & $>300$ \\
\hline
\end{tabular}

WQI can be calculated using the following equation (Brown et al. 1970) [51]

$$
W Q I=\sum_{j=1}^{n} \frac{w i q i}{\sum w i}
$$

Where, wi=unit weight of $\mathrm{jth}$ water quality parameters, qi= Quality rating for the jth parameters.

For calculating the WQI, four steps are required.

Step 1: We have selected two variables $\mathrm{pH}$ and turbidity for calculating the WQI. We use the standard value of the water quality recommended by WHO [46].

Step 2: Quality rating(qi) can be calculated using the following Equation 2.

$$
\mathrm{qi}=\frac{(\mathrm{Va}-\mathrm{Vi})}{(\mathrm{Vs}-\mathrm{Vi})} \times 100
$$

Where, qi =Quality rating for the jth water quality parameters, $\mathrm{Va}$ : The monitored value of the (jth) parameterat a given sampling station, $\mathrm{Vi}$ : ideal value for the jth parameters. For $\mathrm{pH}$, the ideal values is 7.0 and for the turbidity variable the ideal value is $0, \mathrm{Vs}$ : the standard value of jth parameters.

Step 3: Unit weight (wi) can be calculated using the following Equation 3.

$$
w=\frac{K}{S i}
$$

Where, w : unit weight for the jth water quality parameters, Si : standards value for the $\mathrm{jth}$ water quality parameters, $\mathrm{K}$ : relative constant.

Step 4: The calculated WQI values are classified into five groups. Good water quality is given a low range, and bad water quality is given high range of WQI value.

\section{Results Analysis}

In this section, we show how we collect sensors data from our experiment. We also show a hardware simulation of how the temperature, $\mathrm{pH}$ and turbidity sensors are connected to the Arduino Uno R3 board. For collecting the data from the sensor 
node, we use a Thingspeak IoT cloud server. The addition of the GSM module allows the system to be more robust and flexible. GSM module allows the sensors to send data to the IoT cloud server. The data collection procedure is shown in Figure 3.

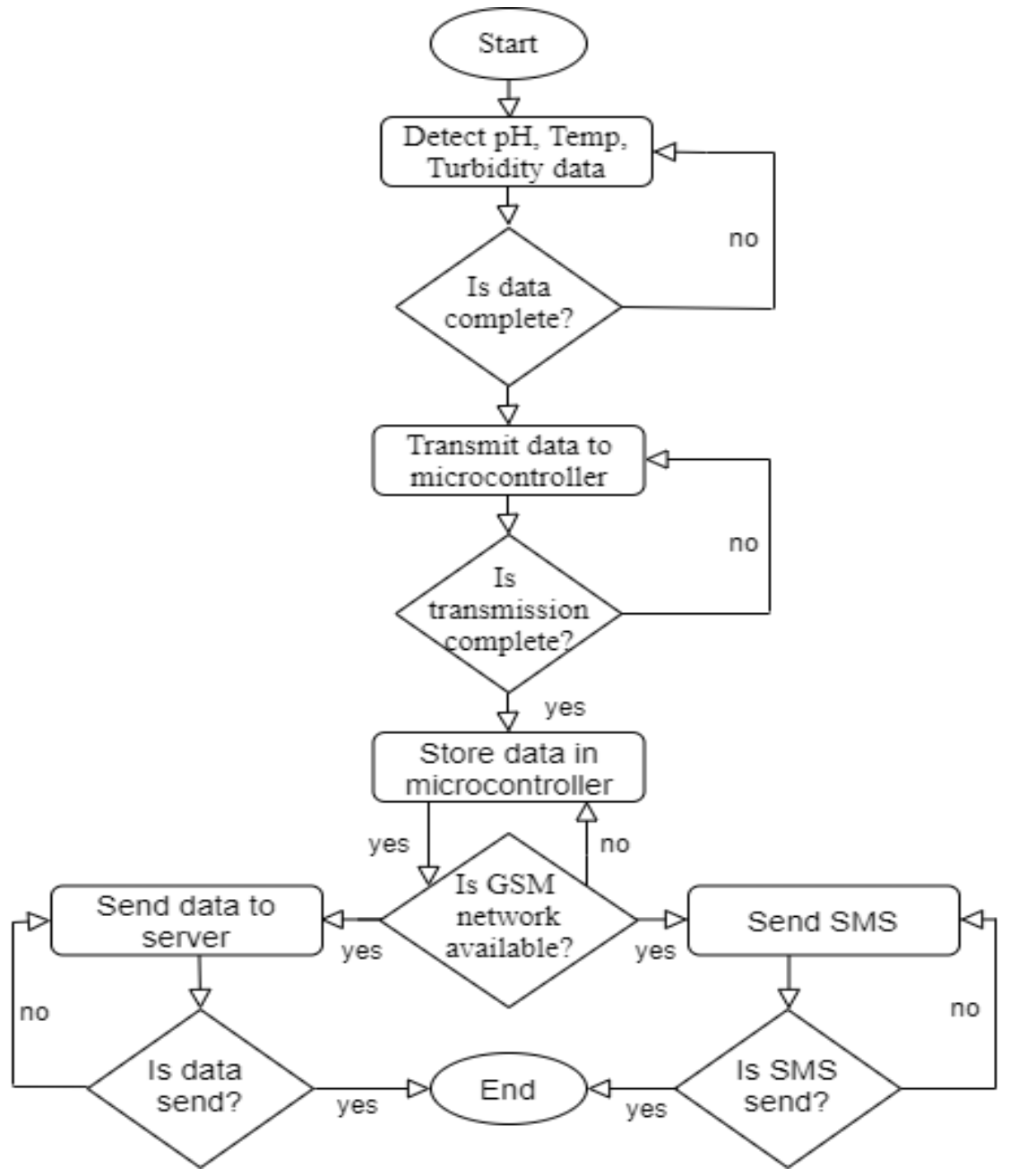

Figure 3

Data Collection Procedure

The optimum $\mathrm{pH}$ range for treated and untreated water are shown in Table 1 . IoT cloud server will send the data to the corresponding PC in real-time, which is shown in Table 3. Table 3 shows the CSV file generated by the Thingspeak server once data from the GSM module is retrieved. Because of the Thingspeak serverinternal mechanisms, the header of this CSV file is fixed to field1, field2, and field3. 
Here, field 1 indicates $\mathrm{pH}$ (ranges from 0 to 14), field 2 indicates temperature (in degrees Celsius), and field 3 indicates turbidity (in Nephelometric Turbidity Unit).

Table 3

Experiment Value

\begin{tabular}{|c|c|c|c|c|c|}
\hline created_at & entry_i & field 1 & field 2 & field 3 & status \\
\hline $2020-01-24$ 11:41:00+06 & 1 & 9.242 & 26.095 & 0 & Treated \\
\hline $2020-01-24$ 11:46:00 +06 & 2 & 9.344 & 25.73 & 0 & Treated \\
\hline $2020-01-24$ 11:51:00+06 & 3 & 9.444 & 26.277 & 0 & Treated \\
\hline $2020-01-24$ 11:56:00+06 & 4 & 9.648 & 25.182 & 0 & Treated \\
\hline $2020-01-24$ 12:01:00+06 & 5 & 9.545 & 25.73 & 0 & Treated \\
\hline $2020-01-24$ 12:06:00 +06 & 6 & 9.495 & 25.365 & 0 & Treated \\
\hline $2020-01-24$ 12:11:00+06 & 7 & 9.091 & 25.182 & 0 & Treated \\
\hline 2020-01-24 12:16:00 +06 & 8 & 8.99 & 24.818 & 445 & Untreated \\
\hline $2020-01-24$ 12:21:00 +06 & 9 & 8.889 & 24.635 & 620 & Untreated \\
\hline 2020-01-24 12:26:00 +06 & 10 & 8.485 & 24.635 & 1942 & Untreated \\
\hline $2020-01-24$ 12:31:00 +06 & 11 & 7.929 & 24.635 & 3 & Treated \\
\hline $2020-01-24$ 12:36:00 +06 & 12 & 8.232 & 24.453 & 1093 & Untreated \\
\hline $2020-01-24$ 12:41:00 +06 & 13 & 8.737 & 24.635 & 2204 & Untreated \\
\hline 2020-01-24 12:46:00 +06 & 14 & 8.737 & 39.599 & 3036 & Untreated \\
\hline $2020-01-24$ 12:51:00 +06 & 15 & 8.333 & 43.613 & 3004 & Untreated \\
\hline $2020-01-24$ 12:56:00 +06 & 16 & 7.727 & 28.102 & 0 & Treated \\
\hline 2020-01-24 13:01:00 +06 & 17 & 9.293 & 25.365 & 1518 & Untreated \\
\hline 2020-01-24 13:06:00 +06 & 18 & 9.404 & 24.635 & 0 & Treated \\
\hline $2020-01-24$ 13:11:00+06 & 19 & 9.646 & 24.635 & 1685 & Untreated \\
\hline
\end{tabular}

From this Table, we show that data is coming to the $\mathrm{PC}$ in real-time. The graphical representation of $\mathrm{pH}$, temperature, and turbidity value is shown in the discussion section. For hardware simulation, we use Fritzing software, which is used primarily for performing schematic capture and allow us to simulate the circuit we design. Using Fritzing software, we simulate how the LM35 temperature sensor, SEN0161 pH meter, and SEN0189 turbidity sensor sends data to the ArduinoUno R3 board. The simulation process is shown in Figure 4. In the simulation process, we con-nect the LM35 VCC pin to the $+5 \mathrm{~V}$ of the Arduino board. As the LM35 output pin produces analog data, so this pin is connected to the 'A1' pin of the Arduino Uno Board. This pin will allow receiving analog values from an exterior origin. The other pinis paired with the GND of the Arduino Uno board. Since pH and temperature sensors are also produced output as analog data, the $\mathrm{pH}$ sensor is connected to the 'A0' pin, and the turbidity sensor is connected to the 'A2' pin of the Arduino Uno Board. The other pin is connected to Arduino Uno as the LM35 temperature sensor is connected. We use a serial monitor from the Arduino IDE software in PC, which is used for checking the values of temperature, $\mathrm{pH}$, and turbidity. The serial monitor looks like the LCD monitor, which is also used for 
showing the parameter values. The calculated WQI values for some of the sample data are shown in Table 4. Comparing the result with our cloud status, it shows an excellent result.

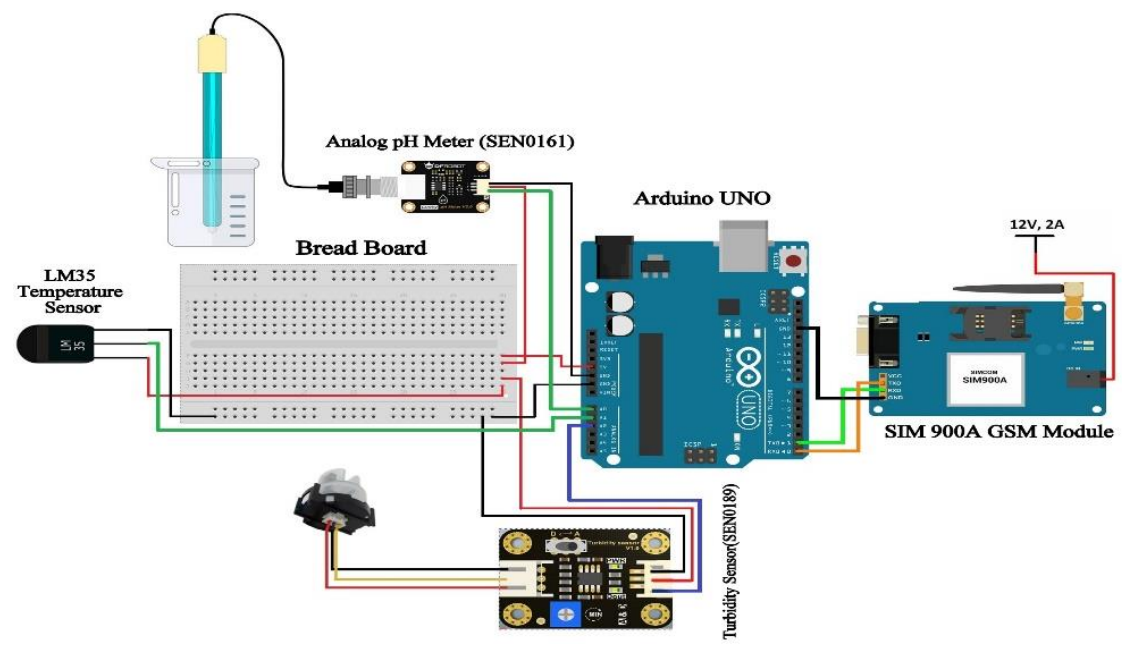

Figure 4

Hardware Simulation Process of Sensors

Although some of the cases can cause problems such as when the cloud server reports that the water quality is treated, but after calculating the WQI, we find that the quality of the water is very poor.

Table 4

WQI values for sample data

\begin{tabular}{|l|l|l|l|}
\hline pH & Turbidity & WQI & Status \\
\hline 9.242 & 0 & 224 & Very Poor \\
\hline 7.929 & 3 & 106 & Poor \\
\hline 8.99 & 445 & 2177 & Unsuitable \\
\hline 8.485 & 1942 & 8780 & Unsuitable \\
\hline 7.727 & 0 & 73 & Good \\
\hline 9.646 & 1685 & 7753 & Unsuitable \\
\hline
\end{tabular}

\section{Discussion}

The proposed method can be implemented in the industry to check water quality in real-time. The results of the method are analyzed and discussed in the context of each scenario. Wireless sensor nodes act as a major role in the whole proposed system. Arduino Uno R3 collects the data from the sensor node. Here, we developed 
a program and uploaded it to the microcontroller, which allows the system to collect data every 5 minutes. Once the data is calculated, the data is passed to the Thingspeak IoT cloud server using a GSM-GPRS model. IoT cloud server will send the data to the $\mathrm{PC}$ in real-time. The performance of the $\mathrm{pH}$, temperature, and turbidity sensor data in the Thingspeak IoT cloud server is shown in Figure 5, 6, 7, which represents how data from the sensor node coming to the Thingspeak IoTcloud server in real-time. Compare to the other methods used for water quality monitoring, our method shows an excellent result and proved to be more effective. Here, our fundamental goal was to monitor the ETP. To monitor the ETP, water quality monitoring is also required. Most of the method used previously is based on just water quality monitoring. In industry to monitor industry wastewater, it is completely a different scenario. Here, we have to consider the environment and also calculate the value in real-time, but most of the methods like paper [15], [16], [31], they use light intensity sensor or turbidity sensor for water quality monitoring. In our method, we use the turbidity sensor, which is more effective in the industry and shows the exact result. Another method like paper [31] they use an ESP32 WiFi module to send the data to the IoT cloud server. For the wifi module, it requires a router to get internet, which may not be possible in the industry. But in our proposed system, we use a GSM module where a SIM-CARD is attached. We can send data to the cloud using the GSM module easily. Thi IoT cloud server is connected to the internet, which uploaded the data into the PC. Using the data, the authority could easily monitor the quality of water. In our program, we also build an emergency situation, when the water quality crosses the danger limit, an emergency SMS will be sent to the corresponding mobile phone. The proposed system gives authorities the ability to check water quality parameters at the industrial water discharge site in real-time. Thus authority can easily monitor whether a particular industry discharged water is polluted or not.

Effluent Treatment Plant Monitoring

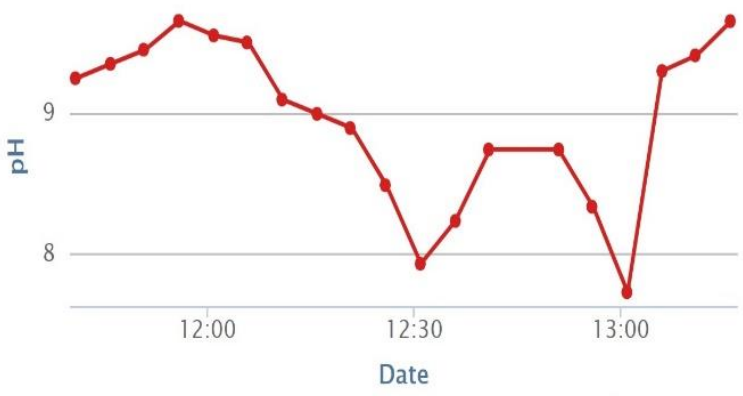

Figure 5

$\mathrm{pH}$ Data in Cloud 


\section{Effluent Treatment Plant Monitoring}

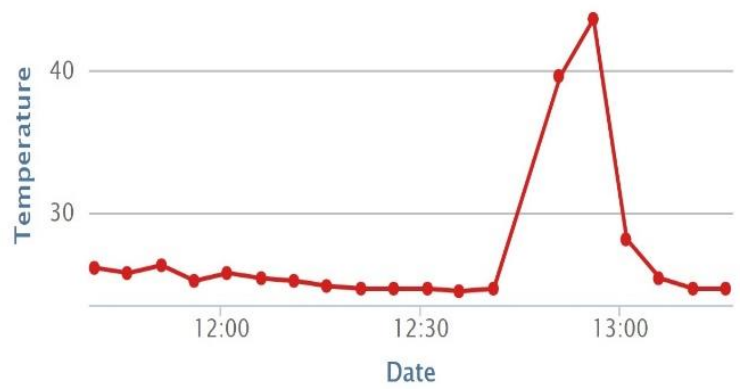

Figure 6

Temperature Data in Cloud

\section{Effluent Treatment Plant Monitoring}

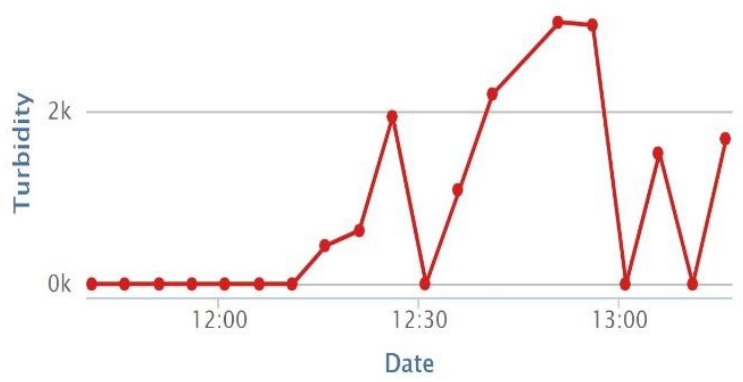

Figure 7

Turbidity Data in Cloud

The status of the data is shown in the Figure 8.

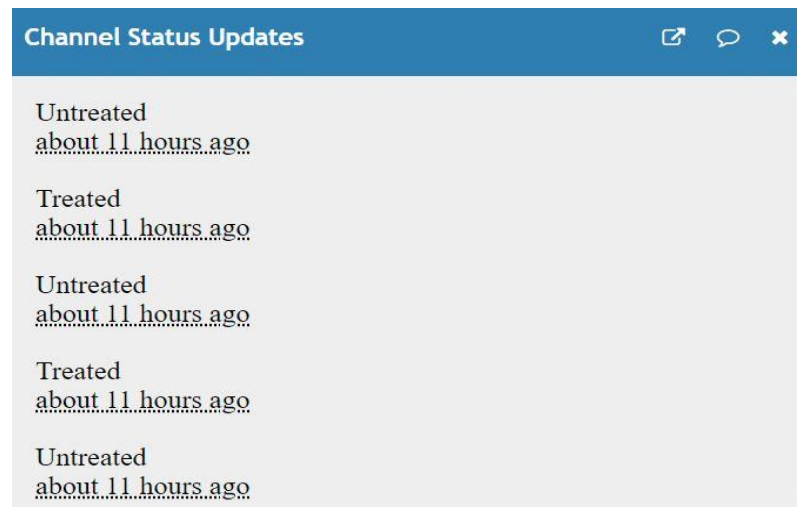

Figure 8

Status 


\section{Conclusion}

In this work, our goal was to monitor the Effluent Treatment Plant using a wireless sensor network in real-time. This proposed system shows an approach for water quality monitoring using a wireless sensor network, which is automated, costeffective, real-time, server-based, and more effective. We already demonstrated our field test result with appropriate calibration, which proves that the system can monitor water quality parameters tirelessly and send those data to the cloud server. Current procedures that are used in Bangladesh are expensive, non-real-time, and time-consuming. The problems that can affect our system are if the internet speed is slow, then the system will take time to send data. In the future, we will use machine learning to detect whether the water is clean or polluted. We will use more advanced software for our simulation purpose.

\section{References}

[1] Rabbi MA, Hossen J, Sarwar M, Roy PK, Shaheed SB, Hasan MM. Investigation of waste water quality parameters discharged from textile manufacturing industries of bangladesh. Current World Environment. $2018 ; 13(2)$

[2] Touhami A, Benahmed K, Bounaama F. Monitoring of Greenhouse Based on Internet of Things and Wireless Sensor Network. InInternational conference on the Sciences of Electronics, Technologies of Information and Telecommunications 2018 Dec 18 (pp. 281-289) Springer, Cham

[3] Gomathi N, Jagtap MA. Smart Agriculture System Towards Iot Based Wireless Sensor Network. Turkish Journal of Computer and Mathematics Education (TURCOMAT) 2021 Jun 5;12(6):4133-50

[4] Rajput A, Kumaravelu VB. Scalable and sustainable wireless sensor networks for agricultural application of Internet of things using fuzzy cmeans algorithm. Sustainable Computing: Informatics and Systems. 2019 Jun 1;22:62-74

[5] Gidlund M, Han S, Sisinni E, Saifullah A, Jennehag U. Guest editorial from industrial wireless sensor networks to industrial internet of things. IEEE Transactions on Industrial Informatics. 2018;4(5):2194-8

[6] Kiani F, Seyyedabbasi A. Wireless sensor network and internet of things in precision agriculture, Vol. 99, 2018, pp. 99-103

[7] Manrique JA, Rueda-Rueda JS, Portocarrero JM. Contrasting internet of things and wireless sensor network from a conceptual overview. In 2016 IEEE international conference on Internet of Things (iThings) and IEEE green computing and communications (GreenCom) and IEEE cyber, physical and social computing (CPSCom) and IEEE smart data (SmartData) 2016 Dec 15 (pp. 252-257) IEEE 
[8] Boonnam N, Pitakphongmetha J, Kajornkasirat S, Horanont T, Somkiadcharoen D, Prapakornpilai J. Optimal plant growth in smart farm hydroponics system using the integration of wireless sensor networks into internet of things. Adv. Sci. Technol. Eng. Syst. J. 2017;2(3):1006-12

[9] Zulkifli CZ, Noor NN. Wireless Sensor Network and Internet of Things (IoT) Solution in Agriculture. Pertanika Journal of Science \& Technology. 2017 Jan $1 ; 25(1)$

[10] Halim, A. A. A., Hassan, N. M., Zakaria, A., Kamarudin, L. M., Bakar, A. H. A. Internet of things technology for greenhouse monitoring and management system based on wireless sensor network (2016) ARPN Journal of Engineering and Applied Sciences

[11] Zhu J, Song Y, Jiang D, Song H. Multi-armed bandit channel access scheme with cognitive radio technology in wireless sensor networks for the internet of things. IEEE access. 2016 Aug 17;4:4609-17

[12] Xiao-Yan A, Dong-Sheng X, Feng Z, Jian-Gang D. Agriculture intelligent control system algorithm for wireless sensor networks based on internet of things. Sensors \& Transducers. 2013 Nov 1;158(11):70

[13] Mainetti L, Patrono L, Vilei A. Evolution of wireless sensor networks towards the internet of things: A survey. In SoftCOM 2011, $19^{\text {th }}$ international conference on software, telecommunications and computer networks 2011 Sep 15 (pp. 1-6) IEEE

[14] Li L, Xiaoguang H, Ke C, Ketai H. The applications of wifi-based wireless sensor network in internet of things and smart grid. In $20116^{\text {th }}$ IEEE Conference on Industrial Electronics and Applications 2011 Jun 21 (pp. 789793) IEEE

[15] M. Parameswari, M. B. Moses, Efficient analysis of water quality measurement reporting system using IOT based system in WSN, Cluster Computing 22 (2019) 12193-12201

[16] Q. Chi, H. Yan, C. Zhang, Z. Pang, L. Da Xu, A reconfigurable smart sensor interface for industrial WSN in IoT environment, IEEE transactions on industrial informatics 10 (2014) 1417-1425

[17] A. Al-Dahoud, M. Fezari, H. Mehamdia, Water Quality Monitoring System Using WSN in Tanga Lake, in: International Conference on Dependability and Complex Systems, Annaba, Algeria, 2019, pp. 1-9

[18] Marques, G., Pitarma, R. An Internet of Things and Wireless Sensor Networks Hybrid Architecture for Precision Agriculture Monitoring (2021) Environmental Science and Engineering, 219, pp. 1863-1867

[19] C. J. H. Pornillos et al., "Smart Irrigation Control System Using Wireless Sensor Network Via Internet-of-Things," 2020 IEEE 12 $2^{\text {th }}$ International Conference on Humanoid, Nanotechnology, Information Technology, 
Communication and Control, Environment, and Management (HNICEM), 2020, pp. 1-6, doi: 10.1109/HNICEM51456.2020.9399995

[20] Sanjeevi P, Prasanna S, Siva Kumar B, Gunasekaran G, Alagiri I, Vijay Anand R (2020) Precision agriculture and farming using internet of things based on wireless sensor network. Trans Emerg Telecommun Technol e3978

[21] Rahman, Anichur and Islam, Md. Jahidul and Rahman, Ziaur and Reza, Md. Mahfuz and Anwar, Adnan and Mahmud, M. A. Parvez and Nasir, Mostofa Kamal and Noor, Rafidah Md., "DistB-Condo: Distributed BlockchainBased IoT-SDN Model for Smart Condominium," in IEEE Access, Vol. 8, pp. 209594-209609, 2020

[22] A. Rahman, M. K. Nasir, Z. Rahman, A. Mosavi, S. S. and B. MinaeiBidgoli, "DistBlockBuilding: A Distributed Blockchain-Based SDN-IoT Network for Smart Building Management," in IEEE Access, Vol. 8, pp. 140008-140018, 2020

[23] Boonnam, N., Pitakphongmetha, J., Kajornkasirat, S., Horanont, T., Somkiadcharoen, D., Prapakornpilai, J. Optimal Plant Growth in Smart Farm Hydroponics System using the Integration of Wireless Sensor Networks into Internet of Things (2017) Advances in Science, Technology and Engineering Systems, Vol. 2, 2017, pp.1006-1012

[24] Abbasi-Kesbi R, Nikfarjam A, Nemati M. Developed wireless sensor network to supervise the essential parameters in greenhouses for internet of things applications $<$ ? show $[\mathrm{AQ}="$ " ID=" Q1]"?. IET Circuits, Devices \& Systems. 2020 Dec 15;14(8):1258-64

[25] Anulekshmi, S., Durga, R. Comprehensive study and research on wireless sensor network and internet of things for precision agriculture (2020) Journal of Advanced Research in Dynamical and Control Systems, Vol. 12, 2020, pp. $150-158$

[26] Yassine, S., Najib, E. K., Fatima, L. Dynamic Cluster Head Selection Method for Wireless Sensor Network for Agricultural Application of Internet of Things based Fuzzy C-means Clustering Algorithm (2019) $7^{\text {th }}$ Mediterranean Congress of Telecommunications 2019, CMT 2019, Faculty of Medicine and PharmacyFez; Morocco; 24 October 2019 through 25 October 2019; Category numberCFP19T86-ART; Code 156056

[27] A. Rahman, M. J. Islam, F. A. Sunny and M. K. Nasir, "DistBlockSDN: A Distributed Secure Blockchain Based SDN-IoT Architecture with NFV Implementation for Smart Cities," $20192^{\text {nd }}$ International Conference on Innovation in Engineering and Technology (ICIET), 2019, pp. 1-6

[28] Islam, M. J., Rahman, A., Kabir, S., Khatun, A., Pritom, A., \& Chowdhury, M. (2021) SDoT-NFV: A Distributed SDN Based Security System with IoT for Smart City Environments. GUB Journal of Science and Engineering, 7, $27-35$ 
[29] A. Faustine, A. N. Mvuma, H. J. Mongi, M. C. Gabriel, A. J. Tenge, S. B. Kucel, Wireless Sensor Networks for Water Quality Monitoring and Control within Lake Victoria Basin, Scientific Research Publishing Inc. 6 (2014)281290

[30] N. Kamal, A. Hammad, T. Salem, M. Omar, EARLY WARNING AND WATER QUALITY, LOW-COST IOT BASED MONITORING SYSTEM, Journal of Engineering Sciences Assiut University Faculty of Engineering 47(2019) 796-808

[31] K. Simitha, S. Raj, IoT and WSN Based Water Quality Monitoring System, in: $20193^{\text {rd }}$ International conference on Electronics, Communication and AerospaceTechnology (ICECA), Coimbatore, India, 2019, pp. 205-210

[32] T.-z. Qiao, L. Song, The design of multi-parameter online monitoring system of water quality based on GPRS, in: 2010 International Conference on Multimedia Technology, Ningbo, China, 2010, pp. 1-3

[33] S. Doshi, S. Dube, Wireless Sensor Network to Monitor River Water Impurity, in: International Conference on Computer Network and Communication Technologies, Pune, India, 2019, pp. 809-817

[34] B. Etikasari, S. Kautsar, H. Riskiawan, D. Setyohadi et al., Wireless sensor network development in unmanned aerial vehicle (uav) for water quality monitoring system, in: IOP Conference Series: Earth and Environmental Science, Politeknik Negeri Jember, Indonesia, 2020, p. 012061

[35] K. H. Kamaludin, W. Ismail, Water quality monitoring with internet of things (IoT), in: 2017 IEEE Conference on Systems, Process and Control (ICSPC), Melaka, Malaysia, 2017, pp. 18-23

[36] S. O. Olatinwo, T.-H. Joubert, Optimizing the energy and throughput of a water-quality monitoring system,Sensors 18 (2018) 1198

[37] Salim TI, Alam HS, Pratama RP, Anto IA, Munandar A. Portable and online water quality monitoring system using wireless sensor network. In $20172^{\text {nd }}$ International Conference on Automation, Cognitive Science, Optics, Micro Electro-Mechanical System, and Information Technology (ICACOMIT) 2017 Oct 23 (pp. 34-40) IEEE

[38] Suryawanshi V, Khandekar M. Design and development of Wireless Sensor Network (WSN) for water quality monitoring using Zigbee. In 2018 Second International Conference on Intelligent Computing and Control Systems (ICICCS) 2018 Jun 14 (pp. 862-865) IEEE

[39] Jegadeesan S, Dhamodaran M, Shanmugapriya SS. Wireless Sensor Network based Flood and Water Quality Monitoring System using IoT. Taga journal of graphic technology, Online ISSN. 2018(1748-0345) 
[40] L. N. Devi, G. K. Reddy, A. N. Rao, Live demonstrationon smart water quality monitoring system using wireless sensor networks, in: 2018 IEEE SENSORS, New Delhi, India, 2018, pp. 1-4

[41] A. T. Demetillo, M. V. Japitana, E. B. Taboada, Asystem for monitoring water quality in a large aquatic area using wireless sensor network technology, Sustainable Environment Research 29 (12)

[42] U. Ahmed, R. Mumtaz, H. Anwar, A. A. Shah, R. Irfan, J. Garc' 1a-Nieto, Efficient water quality prediction usingsupervised machine learning, Water 11 (2019) 2210

[43] S. Hafeez, M. S. Wong, H. C. Ho, M. Nazeer, J. Nichol, S. Abbas, D. Tang, K. H. Lee, L. Pun, Comparison of machine learning algorithms for retrieval of water quality indicators in case-ii waters: a case study of hong kong, Remote sensing 11 (2019) 617

[44] Khan MS, Islam N, Uddin J, Islam S, Nasir MK. Water Quality Prediction and Classification Based on Principal Component Regression and Gradient Boosting Classifier Approach. Journal of King Saud University-Computer and Information Sciences. 2021 Jun 14

[45] R. Barzegar, M. T. Aalami, J. Adamowski, Short-term water quality variable prediction using a hybrid cnn-lstm deep learning model, Stochastic Environmental Researchand Risk Assessment (2020) 1-19

[46] Guidelines for drinking-water quality, third edition Edi-tion, World Health Organization, Geneva, 2004

[47] A. Rahman, M. J. Islam, M. Saikat Islam Khan, S. Kabir, A. I. Pritom and M. Razaul Karim, "Block-SDoTCloud: Enhancing Security of Cloud Storage through Blockchain-based SDN in IoT Network," $20202^{\text {nd }}$ International Conference on Sustainable Technologies for Industry 4.0 (STI), 2020, pp. 16

[48] Rahman, Anichur and Islam, Md. Jahidul and Montieri, Antonio and Nasir, Mostofa Kamal and Reza, Md. Mahfuz and Band, Shahab S. and Pescape, Antonio and Hasan, Mahedi and Sookhak, Mehdi and Mosavi, Amir, "SmartBlock-SDN: An Optimized Blockchain-SDN Framework for Resource Management in IoT," in IEEE Access, Vol. 9, pp. 28361-28376, 2021

[49] M. Kachroud, F. Trolard, M. Kefi, S. Jebari, G. Bourri' e, Water quality indices: Challenges and application limits in the literature, Water 11 (2019) 361

[50] C. Ramakrishnaiah, C. Sadashivaiah, G. Ranganna, Assessment of water quality index for the ground water in tumkur taluk, karnataka state, india, Journal of Chemistry 6 (2009) 523-530

[51] Brown RM, McClelland NI, Deininger RA, Tozer RG. A water quality index-do we dare. Water and sewage works. 1970 Oct; 117(10) 